\title{
Scanning Electron Microscopic Characterization and Elemental Analysis of Hair: A Tool in Identification of Felidae Animals
}

\section{Dahiya MS1 and Yadav SK2*}

${ }^{1}$ Director, Institute of forensic science and Dy. Director, DFS Gujarat State, India

${ }^{2}$ Forensic Wildlife Biotechnology Research Laboratory, IFS GFSU, India

\begin{abstract}
Within the forensic identification the study of animal hair has remain limited to cross-species comparisons from the same family but there is also considerable changes in those animals like scale layer differentiation growth pattern, tensile strength, granulation and elemental profile of the animal hair. Here a rapid method is described for assessing a variety of morphological characteristics for identification of species that could be easily used by forensic investigators to identify the hairs from different species by just a fraction of single hair sample using Scanning Electron Microscope (SEM). Hair samples from 90 animals of Felidae family, 30 from each Panthera leo persica (lion), Panthera paradus fusca (Leopard) and Panthera tigris tigris (Tiger) were examined for their cuticular scale layer difference pattern and measurements were taken using SEM annotations. Significant differences were observed in scale layer pattern differences/difference in overlapping of each scale in hair which can be used in identification of the species. The difference between each layer was observed as $6.72431 \pm 0.4,7.869655 \pm 0.38$ and $9.592897 \pm 0.5$ $\mu \mathrm{m}$ for Panthera Leo persica, Panthera tigris tigris and Panthera pradus fusca. Elemental analysis for all the three species from Felidae family have been evaluated using Energy Dispersive Spectrum coupled with SEM for analysis of Sodium, Potassium, Calcium and Sulfur. Significant results were obtained are can be further used to establish a concordance with the species identification.
\end{abstract}

Keywords: Hair examination; SEM-EDS; Hair scale pattern; Elemental analysis; Species identification; Felidae animals; Microscopy

\section{Introduction}

India is referred to have among richest biodiversity nations of the world [1] having mixture of Palaearctic, Oriental and Afro-tropical fauna [2]. India is home for 400 mammal species out of which 129 species are protected under Wildlife (Protection) Act 1972 (India) and a arbitrator to Convention on International Trade in Endangered Species (CITES) [3]. Illegal trade of the wildlife products are key risk to conservation and responsible for regional obliteration to these species. According to earlier findings wildlife products are third in the row of illegal trade after narcotics and firearms $[1,4]$. Products of illegal wildlife trade includes meat, antler, horns, nails, bones, horns, musk, ivory, biles, pods, skin fur, claws, teeth and wool etc which are traded in various forms like processed leather, brushes, frames, ornaments, showpieces and also in traditional medicines (Chinese) (TCM) [5]. The use of hair in studying taxonomy, environmental factor and work culture has been explored by various scientists. Researches has revealed about the hair scale pattern and medullary index using light microscopy as well as electron microscopy [6].

Researchers from diverse fields counting veterinary sciences, taxonomy, wildlife biology, forensic wildlife, the textile industry and forensic medicine, have used the micro-morphological characterization of different types of hairs for investigating crime and suspected samples [7]. Determination keys for getting accurate identification are based on macroscopic features such as size, shape, profile and colour of the hairs, scale pattern similarly microscopic characteristics of the cortex medulla and cuticle structure [8]. Although, the identification is problematical by the occurrence of significant discrepancy caused by differences of species, breed and gender of the animals, by environmental conditions (climate, habitat, nutrition) and possibly also by the body region from which the hairs are derived [9] so to overcome these effects and to raise the integrity of the results, hairs from different body regions from animals of four different regions belonging to different age groups were selected for studying the accurate differences in preparation of standard reference measurements.

Now a day, the crime related to animals of high economic impact (Scheduled under Wildlife Protection Acts) has gained specific focus where hair can be used for identification of the animals in issues related to species identification, [10] but this demands reference samples for the examination. Reference sample collection for each case from zoos, wildlife rescue centers and museums is a lengthy task to perform examination based on microscopy between closely associated species like tiger, lion, and leopard since they belongs to the same family. The animals are mostly poached for their meat, skin, bones, claws, nails and ivory etc where hair can be used to identify the species [11]. Hair plays a vital role as the key evidence found in cases related to wildlife crimes of these species [12]. This evidence will lead to the identification of species with the help of Scanning Electron Microscope (SEM) and can be utilized for the identification of the animals [13]. Scanning electron microscopy provides higher range of magnification and coupled Energy Dispersive Spectra (EDS) which will leads to the identification of geographical region by elemental analysis can be used further for other examinations [14]. A comprehensive microscopic hair characteristic atlas of indigenous mammals of Australia have been reported earlier in which the hair scale pattern of different species have been incorporate [15]. Similarly, a key atlas on microscopic hair characters of west

*Corresponding author: S K Yadav, Forensic Wildlife Biotechnology Research Laboratory, IFS GFSU, India, Tel.+91-99789-11007; E-mail: sameerforensics@gmail.com

Received March 08, 2012; Accepted April 05, 2013; Published April 23, 2013

Citation: Dahiya MS, Yadav SK (2013) Scanning Electron Microscopic Characterization and Elemental Analysis of Hair: A Tool in Identification of Felidae Animals. J Forensic Res 4: 178. doi:10.4172/2157-7145.1000178

Copyright: () 2013 Dahiya MS, et al. This is an open-access article distributed under the terms of the Creative Commons Attribution License, which permits unrestricted use, distribution, and reproduction in any medium, provided the original author and source are credited. 
European mammals has been published [16]. Examination hair have been widely used for taxonomic identification has been reported for few species. Hair sample can be used for genomic and mitochondrial DNA analysis and other chemical tests can also be subjected to go for individual identification. But till date, not so much validated methods for hair examination regarding intra-family species identification are available using just a fraction of hair. As growth pattern and life span of the animals from same family varies significantly [17]. Based on the growth of the animals, hair scale pattern and its growth also varies from species to species [18]. Current study shows that how hair variesbetween species and how he developed a database of mammal hair that can be used by wild life forensic scientists in investigating cases of illegal trafficking of the world's most endangered animals [19]. Hair samples from some wild animals were evaluated in this study. SEM of the scale pattern was investigated for identification of scale pattern difference in three closely related species from the family Felidae including Panthera leo persica, Panthera pradus fusca and Panthera tigris tigris. The ongoing research on microscopic characteristics of hair can be used to offer more information for wildlife forensics and provide vital information for the identification of prohibited transfer of animals, poaching or wildlife crime, fraud in textile and fur industry, and recognition of their victims, etc.

\section{Materials and Methods}

\section{Reagents}

Absolute alcohol, SDS, $\mathrm{HNO}_{3}, \mathrm{H}_{2} \mathrm{O}_{2}$, Rectified Spirit used were analytical grade reagents procured from Hi-Media and Merck specialties. Carbon tape, aluminum adhesive and gold-palladium coating material was taken from ZEISS SEM supplies.

\section{Sample collection}

Hairs of lion, leopard and tigers were collected from Indroda nature park, Gandhinagar ( $\left.23^{\circ} 11^{\prime} 32.70^{\prime \prime} \mathrm{N}, 72^{\circ} 39^{\prime} 03.04^{\prime \prime} \mathrm{E}\right)$; Kamala Nehru Zoological Garden Kankaria, Ahmedabad (2300'34.11"N,

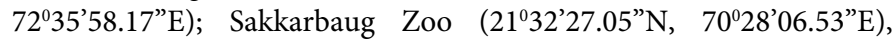
Wildlife Rescue Center Junagadh $\left(21^{0} 32^{\prime} 56.82^{\prime \prime} \mathrm{N}, 70^{\circ} 28^{\prime} 23.44^{\prime \prime} \mathrm{E}\right)$ wide letter No. WLP/28/B/4651-54/2012-13 from the Office of the Principle Chief Conservator of Forests and Chief Wildlife Warden, Gujarat State. 10 hair of each of 90 animals, 30 samples from each of the three species i.e. Panthera leo persica, Panthera tigris tigris and Panthera pradus fusca were taken for the study. The hairs were taken from the cage and enclosure (Including Shaded hairs possibly being from different body parts) using forceps with gloves to avoid contamination and were packed in zip-lock bags followed by paper envelops. Geographical locations were identified by "Bhaskaracharya Institute of Space Applications and Geo-Informatics", Gandhinagar, INDIA.

\section{Sample preparation}

Hair samples were washed with absolute alcohol followed by washing in $2 \%$ SDS, rinsed, repeated these steps three times, dried at room temperature for about 24 hours followed by packing in fresh ziplock bags and stored at $0^{\circ} \mathrm{C}$ till further analysis. For Scanning electron microscopy hair samples were dissected in pieces of $5 \mathrm{~mm}$ size leaving $3 \mathrm{~mm}$ from root side and placed on sample holder followed by plasma Gold-Palladium coating at 5 milibar vacuum and $5 \mathrm{~mA}$ current for 105 seconds.

\section{SEM-EDS analysis}

The samples were examined under Scanning Electron Microscopy
[SEM] using Zeiss EVO 18 Special edition for imaging and elemental analysis. Examination was done with working distance (WD) of $7 \mathrm{~mm}$ and Electron Gun frequency at $10 \mathrm{kV}$ for imaging at a line integral of $\mathrm{n}=50$ and 24 bit imaging software mode provided with SEM Workstation, and at WD of $9.5 \mathrm{~mm}$ Gun Beam on $20 \mathrm{kV}$ using Energy dispersive Spectrum detector provided by Oxford Instruments. For EDS, Dot-Id setup is used for Sulfur (S), Iron (Fe),

Potassium (K), and Calcium (Ca) elements in hair. The elements present inside the hair were tested for both intra and inter animal differences using element Percentage and atomic percentage analysis

For getting the clarity in the results 10 hair samples of different body parts of 30 different animals for each species were measured using SEM software digital scale. Selection of specific measuring points for getting accurate scale differentiation between each layer has been made on the bases of the angle between the planes of the hair due to irregular pattern a \pm 10 degree of the angle was selected for measurement which was further justified by measuring at least 10 different scales for each hair. 300 different hairs from 30 animals were tested for measurements for all the three species and difference in the measurements were further cross checked at various magnifications i.e. $500 \mathrm{X}, 1000 \mathrm{X}$, 2000X simultaneously and raised up to $7500 \mathrm{X}$ for some samples to maintain the accuracy using annotations present in the software EM Server. The systematic examination using various instruments resulted in detection of the elements with their corresponding quantities. These have shown the constituent concentrations of the elements that are present in hair samples.

\section{Results}

There is a significant difference in scale layers between all three species of the animals have been observed and shown a close variation between intra-species from all the samples. The variation between intra-species were tested statistically and $\mathrm{p}<0.01$ while it is observed with a significant difference in inter-species comparison where the distance between each layer of hair scale was observed in 30 animals from 10 samples of each animal for all three species and observed the scale difference between each layer ranges from $6.367 \mu$ meter to $6.948 \mu$ meter in Asiatic Lion, from $7.758 \mu$ meter-7.992 $\mu$ meter for tiger while it ranges from 8.63-9.884 $\mu$ meter in case of leopard (Table 1). The scale pattern differences have observed at different magnifications i.e. 500X and 200X and also magnified more than $7500 \mathrm{X}$ for verifying the accuracy. Elemental profiling have observed under SEM-EDS. The measurements are based on the digital scale of SEM software at multiple positions in each hair during the analysis as shown in Figures 1-6. These measurements were taken at different points to avoid the bias by using the angles, +10 from the angle/plane of the hair in the frame during the measurements because of the non-consistent differences in shape of the hair scales.

The scale pattern difference of Panthera leo persica have been observed at three different magnifications i.e. 500X, 2000X and 7.58KX as shown in Figures 1-3 where the constant differences in the scales were observed with minor variations from 6.367-9.948 $\mu$ meter from all the sides of the body hairs fallen naturally from the body, inside the enclosure of the animal for all 30 animals.

The differences between scale layers of Panthera pradus fusca using SEM have revealed the differences with a significant variation from all the remaining two species of Felidae family under study that ranges between 8.63-9.884 $\mu$ meter, shown in Figure 4 while the difference among animals of species Panthera tigris tigris were observed to have a range of 7.758-7.992 $\mu$ meters shown in Figure 5 and 6. 
Citation: Dahiya MS, Yadav SK (2013) Scanning Electron Microscopic Characterization and Elemental Analysis of Hair: A Tool in Identification of Felidae Animals. J Forensic Res 4: 178. doi:10.4172/2157-7145.1000178

\begin{tabular}{|c|c|c|c|}
\hline \multicolumn{4}{|c|}{ Average Hair scale measurements (in $\mu \mathrm{m}$ ) per animal } \\
\hline S.No & Lion & Leopard & Tiger \\
\hline 1 & 6.753 & 9.438 & 7.903 \\
\hline 2 & 6.569 & 9.661 & 7.822 \\
\hline 3 & 6.705 & 9.54 & 7.874 \\
\hline 4 & 6.881 & 9.692 & 7.845 \\
\hline 5 & 6.663 & 9.438 & 7.965 \\
\hline 6 & 6.819 & 9.5 & 7.997 \\
\hline 7 & 6.837 & 9.602 & 7.758 \\
\hline 8 & 6.808 & 9.112 & 7.998 \\
\hline 9 & 6.569 & 8.63 & 7.954 \\
\hline 10 & 6.837 & 9.46 & 7.903 \\
\hline 11 & 6.746 & 8.991 & 7.779 \\
\hline 12 & 6.367 & 9.602 & 7.753 \\
\hline 13 & 6.857 & 9.734 & 7.768 \\
\hline 14 & 6.836 & 9.848 & 7.922 \\
\hline 15 & 6.872 & 9.781 & 7.992 \\
\hline 16 & 6.857 & 9.884 & 7.753 \\
\hline 17 & 6.436 & 9.68 & 7.958 \\
\hline 18 & 6.705 & 9.753 & 7.931 \\
\hline 19 & 6.598 & 9.837 & 7.968 \\
\hline 20 & 6.634 & 9.753 & 7.763 \\
\hline 21 & 6.79 & 9.592 & 7.997 \\
\hline 22 & 6.471 & 9.663 & 7.869 \\
\hline 23 & 6.905 & 9.569 & 7.832 \\
\hline 24 & 6.843 & 9.881 & 7.882 \\
\hline 25 & 6.83 & 9.663 & 7.823 \\
\hline 26 & 6.77 & 9.724 & 7.995 \\
\hline 27 & 6.948 & 9.691 & 7.729 \\
\hline 28 & 6.581 & 9.701 & 7.84 \\
\hline 29 & 6.518 & 9.558 & 7.823 \\
\hline 30 & 6.724 & 9.808 & 7.693 \\
\hline Average & 6.72431 & 9.592897 & 7.869655 \\
\hline
\end{tabular}

Table 1: Shows the average hair scale layer difference measurements of each animal from all three species Lion Leopard and Tiger.

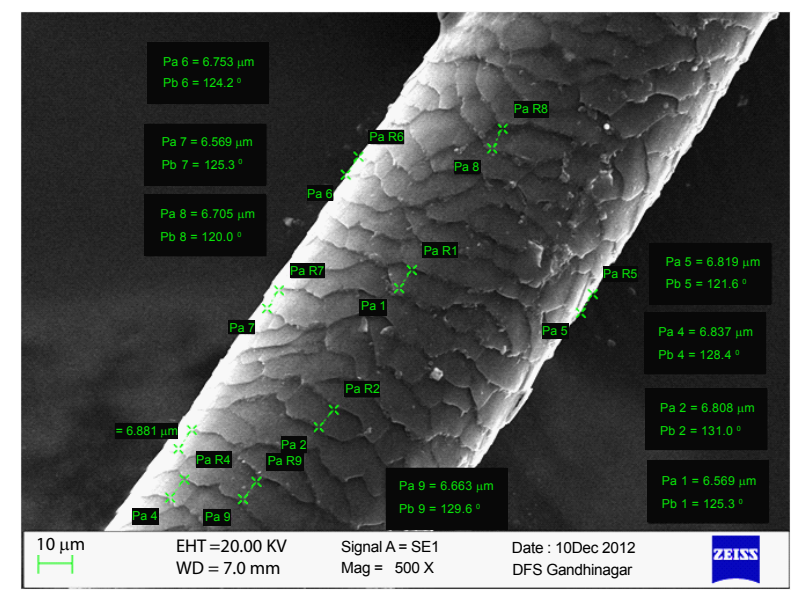

Figure 1: Showing scale pattern and difference in scale layers of Panthera leo Persica at 500X and 2000X.

Elemental analysis using SEM-EDS have revealed about the percentage of Sodium, Sulfur, Calcium and Potassium on the basis of weight $\%$ and Atomic \% respectively as shown in Tables $2-4$ that revealed the metal concentration in Panthera leo persica, Panthera tigris tigris and Panthera pradus fusca among all samples of the species

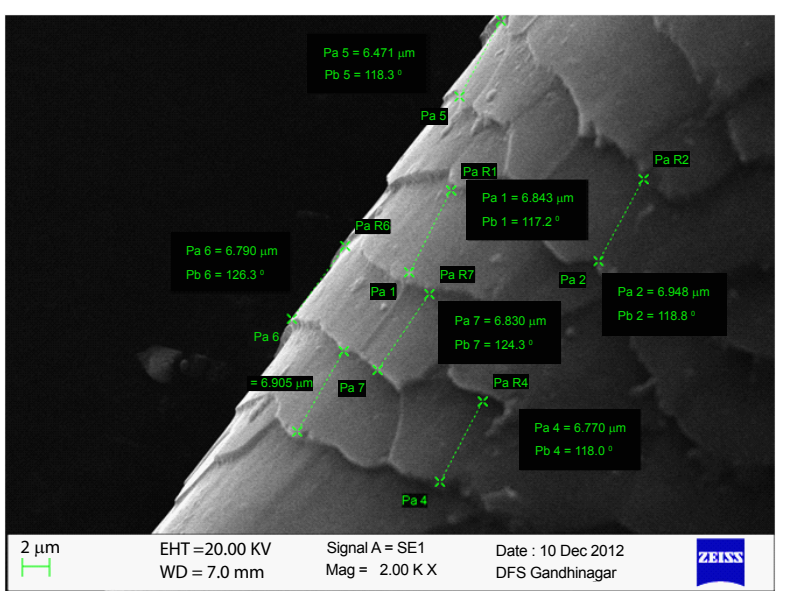

Figure 2: Showing scale pattern and difference in scale layers of Panthera leo Persica at 500X and 2000X.

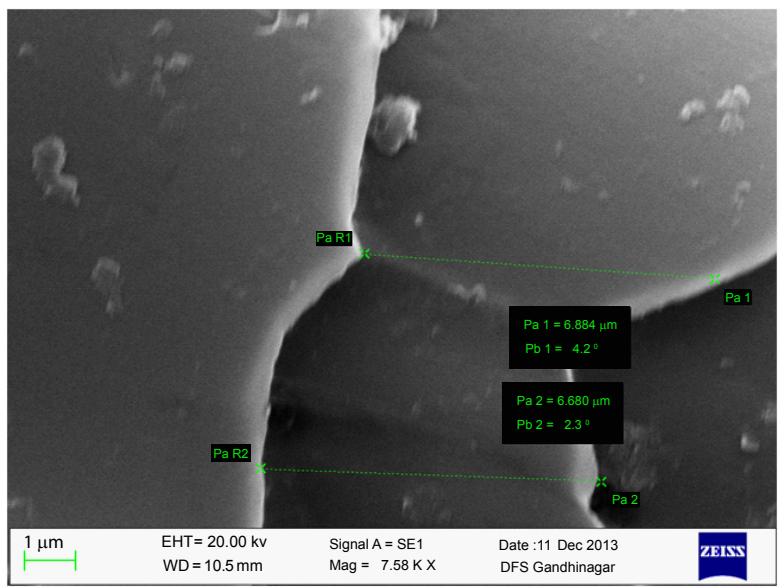

Figure 3: showing hiar scale pattern differences of Panthera leo parsica at $7580 X$.

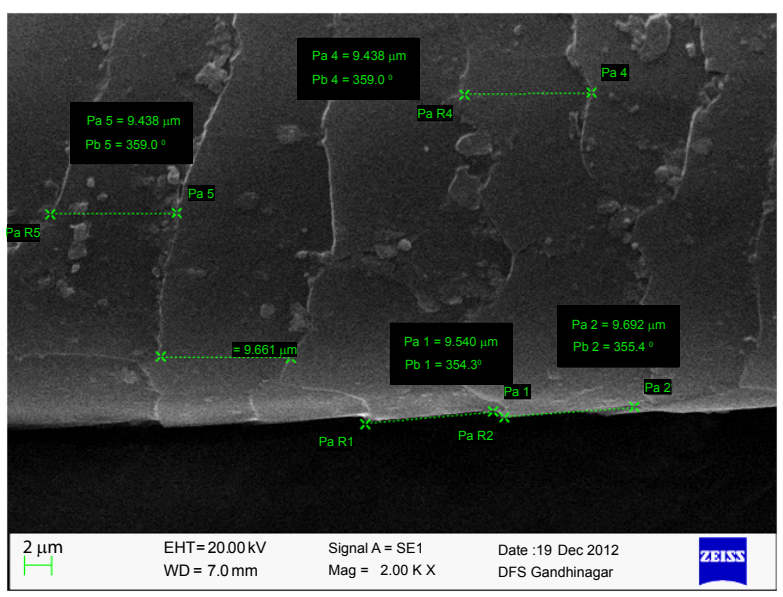

Figure 4: Showing scale pattern and difference in scale layers of Panthera pradus fusca at $2000 \mathrm{X}$ 
Citation: Dahiya MS, Yadav SK (2013) Scanning Electron Microscopic Characterization and Elemental Analysis of Hair: A Tool in Identification of Felidae Animals. J Forensic Res 4: 178. doi:10.4172/2157-7145.1000178

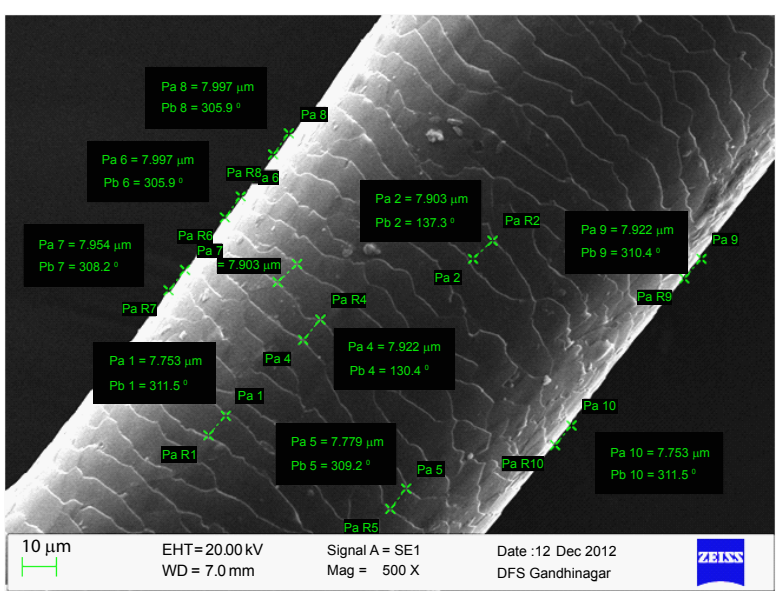

Figure 5: Showing scale pattern and difference in scale layers of Panthera tigris tigris at $500 \mathrm{X}$ and $2000 \mathrm{X}$.

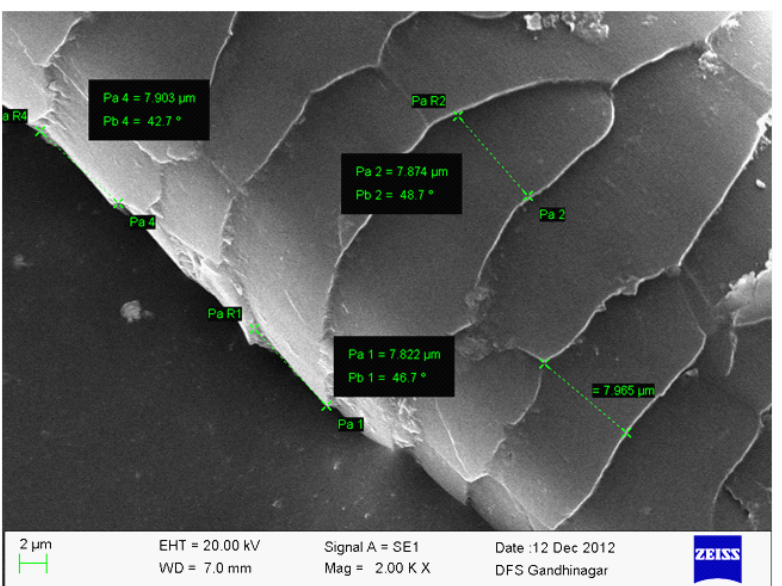

Figure 6: Showing scale pattern and difference in scale layers of Panthera tigris tigris at $500 \mathrm{X}$ and $2000 \mathrm{X}$

where $\mathrm{p}<0.01$. SEM-EDS study of species of the Felidae family have revealed about the weight and Atomic percentage of sodium, Sulfur, Potassium, and Calcium. EDS analysis has been done for elemental concentration of $\mathrm{Na}, \mathrm{K}, \mathrm{Ca}$ and $\mathrm{S}$, all other elements were removed from the element profile console of the instrument software and thus total concentration of these given elements have been analyzed (Figures 7-12). The concentration of these elements was found to be significant and same with minor changes in the animals from all the four locations for each species. Thus these findings can be employed for further analysis in forensic identification of these species along with scanning electron microscopy.

The elemental analysis was done for all the hair samples from each 30 animals of three different species and tested statistically for their significance using chi square test, $\mathrm{T}$ test and $\mathrm{P}$ value where they were found to be significant.

\section{Discussion}

The use of scanning electron microscopy in wildlife forensic cases has been described for species identification [20]. The surface cuticular pattern, cross section and medullary index provides the information regarding the species [21]. Researchers have revealed the scale architecture of regular mosaic with smooth margins of shahtoosh wool. But when the hair evidence from different species from the same family were found to be blended together than the investigation becomes quite tough and typical so the present study which incorporates the scale layer difference between closely related species can provide the information regarding its species to the forensic expert. Elemental analysis through EDS provides significant information of the hair sample of specific

\begin{tabular}{|c|c|c|}
\hline Element & Weight $\%$ & Atomic\% \\
\hline Na K & 4.14 & 5.99 \\
\hline S K & 53.32 & 55.31 \\
\hline Ca K & 28.81 & 27.02 \\
\hline K K & 13.73 & 11.68 \\
\hline Totals & 100.00 & \\
\hline
\end{tabular}

Table 2: Showing the average elemental analysis of the hair samples with an variability not more than \pm 0.1 for the hairs between the same animal and at an standard deviation of not more than \pm 0.5 for inter animal for each 30 animals i.e. Panthera leo persica, Panthera pradus fusca and Panthera tigris tigris.

\begin{tabular}{|c|c|c|}
\hline Element & Weight $\%$ & Atomic\% \\
\hline Na K & 2.62 & 3.75 \\
\hline $\mathrm{S} \mathrm{K}$ & 50.08 & 54.45 \\
\hline $\mathrm{K} \mathrm{K}$ & 5.75 & 5.65 \\
\hline Ca K & 41.56 & 36.15 \\
\hline Totals & 100.00 & \\
\hline
\end{tabular}

Table 3: Showing the average elemental analysis of the hair samples with an variability not more than \pm 0.1 for the hairs between the same animal and an standard deviation of not more than \pm 0.5 for inter animal for each 30 animals i.e. Panthera leo persica, Panthera pradus fusca and Panthera tigris tigris.

\begin{tabular}{|c|c|c|}
\hline Element & Weight $\%$ & Atomic\% \\
\hline Na K & 4.88 & 6.81 \\
\hline S K & 85.04 & 85.02 \\
\hline K K & 5.76 & 4.72 \\
\hline Ca K & 4.32 & 3.45 \\
\hline Totals & 100.00 & \\
\hline
\end{tabular}

Table 4: Showing the average elemental analysis of the hair samples with an variability not more than \pm 0.1 for the hairs between the same animal and at an standard deviation of not more than \pm 0.5 for inter animal for each 30 animals i.e. Panthera leo persica, Panthera pradus fusca and Panthera tigris tigris.

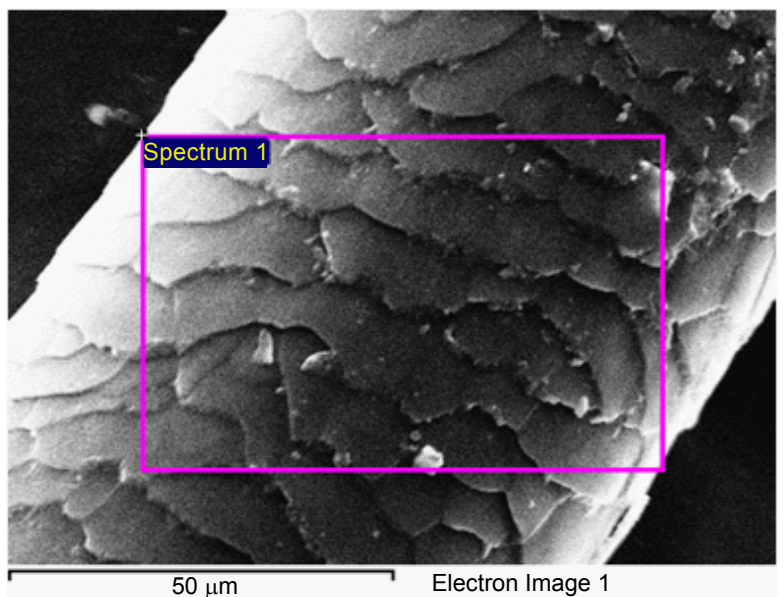

Figure 7: Showing the area selected for EDS and elemental analysis observed using SEMEDS by INCA dot id setup for element detection for Panthera leo persica. 
Citation: Dahiya MS, Yadav SK (2013) Scanning Electron Microscopic Characterization and Elemental Analysis of Hair: A Tool in Identification of Felidae Animals. J Forensic Res 4: 178. doi:10.4172/2157-7145.1000178

sample which can further be used as a geographical region and species identification tool. The area selected for EDS and elemental analysis for Panthera leo persica, Panthera pradus fusca and Panthera tigris tigris are shown in Figures 7-12 respectively. SEM and SEM-EDS requires just a fraction of hair sample and provides vital information regarding the sample which leads to the criminal identification as in detection of Species, occupational exposure which is present inside the hair sample due to environmental exposure and sometimes the geographical area if the soil particles were recovered from SEM and SEM-EDS analysis. Although there is a vast range of literature available regarding medullary index, scale pattern, pigmentation and growth there is a need to develop the database of the differentiation in scale layers which does not only provide the information regarding species but also give slue regarding his disease history as well as environmental exposure with the help of techniques like SEM. EDXRF, EDS etc. This study will work as a tool / primary source in forming the database of the scale layer pattern for the identification of closely related species

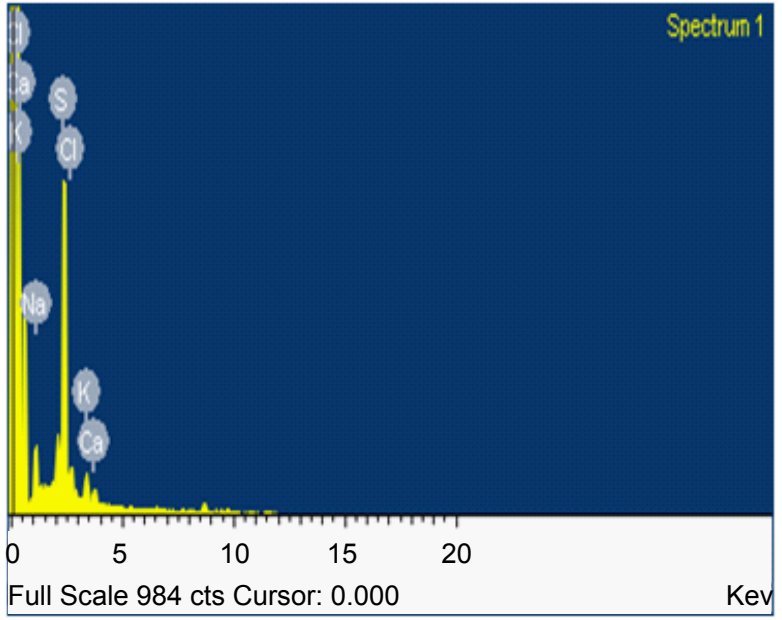

Figure 8: Showing the area selected for EDS and elemental analysis observed using SEMEDS by INCA dot id setup for element detection for Panthera leo persica.

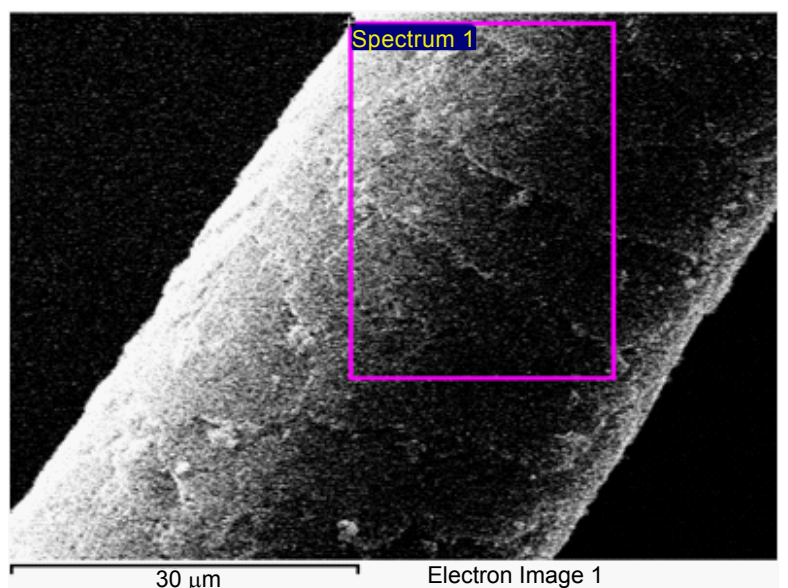

Figure 9: Showing the area selected for EDS and elemental analysis observed using SEMEDS by INCA dot id setup for element detection for Panthera pradus fusca.

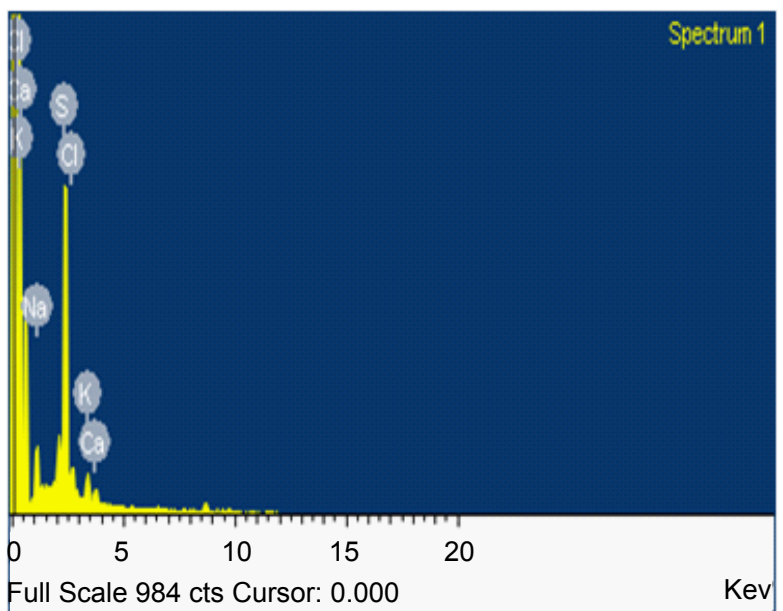

Figure 10: Showing the area selected for EDS and elemental analysis observed using SEMEDS by INCA dot id setup for element detection for Panthera pradus fusca.

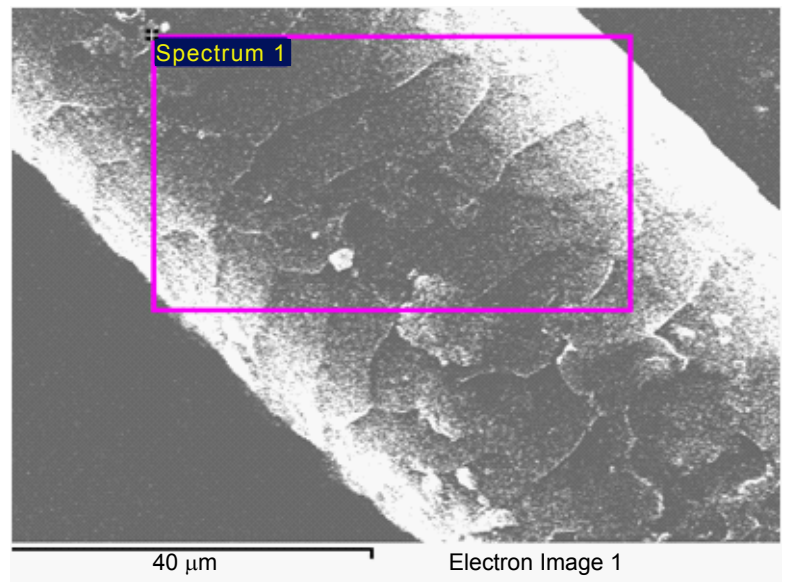

Figure 11: Showing the area selected for EDS and elemental analysis observed using SEMEDS by INCA dot id setup for element detection for Panthera tigris tigris.

from the same family where the examiner faces problems regarding identification.

DNA screening has proved its use in trace evidence identification but in some cases of wildlife artifacts it is difficult to isolate the DNA from hair shafts and even it is difficult to isolate adequate amount of DNA for screening from 1-2 hairs and also the main problem which persists in the DNA examination is that it is a destructive technique thus the evidence will get consumed, needs expertise and also not rapid and cost effective that SEM examination for analysis and can further be used for DNA screening.

Present study have been conducted to identify the differences between three closely related species of the felidae family those were having more than 80 percent of similarity in their scale pattern while the same study have not been tested with the forms of domestic cats as they shows a clear difference in their scale pattern and shows clear coronal scale pattern of the presence of cat hair. As domestic cats shows a clear shape of the hair scale pattern which can be easily differentiated 
Citation: Dahiya MS, Yadav SK (2013) Scanning Electron Microscopic Characterization and Elemental Analysis of Hair: A Tool in Identification of Felidae Animals. J Forensic Res 4: 178. doi:10.4172/2157-7145.1000178

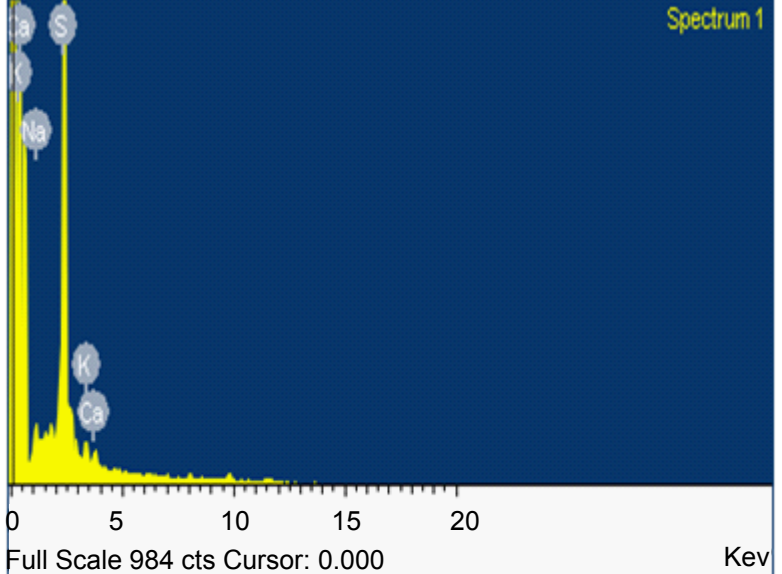

Figure 12: Showing the area selected for EDS and elemental analysis observed using SEMEDS by INCA dot id setup for element detection for Panthera tigris tigris.

from the Lion, leopard and Tiger hair scale although they are from the same family.

\section{Conclusion}

Although our studies were performed with a small sample size, our results are based on the morphology, elemental analysis and cuticular scale pattern of the hair obtained using most advanced investigational methods clearly shows the new finding previously not reported in identification of hair. Our study provides a clear and significant research results for the identification of closely related species on the bases of their scale layer difference and elemental analysis profile pattern.

The second major conclusion of work is that it provides a vital information regarding identification of three different species from the Felidae family on the bases of their scale layer differentiation pattern whereas it was quite difficult to identify them on the bases of previously reported literature and provides a new area for the identification of hairs.

\section{Acknowledgements}

The authors are grateful to Mr. S. K. Goyal (Indian Forest Services), PCCF and Chief Wildlife Warden, Gujarat State for providing the permission of the research on Felidae animals, and to Mr. Sanjay Prajapati for providing SEM-EDS Services from Physics Division, Directorate of Forensic Sciences, Gujarat State. Gandhinagar, India.

\section{References}

1. Sahajpal V, Goyal SP, Raza R, Jayapal R (2009) Identification of mongoose (genus: Herpestes) species from hair through band pattern studies using discriminate functional analysis (DFA) and microscopic examination. Sci Justice 49: 205-209.

2. Sahajpal V, Goyal SP (2006) Microscopic hair characteristics: A tool for dealing wildlife offences in India. Annual meeting of the European Hair Research Society (EHRS) London, U.K: Imperial College.

3. De JK, Chakraborty S, Chakraborty R (1998) Identification of Dorsal Guard Hairs of five Indian Species of Mongoose. Herpestes Illiger (Mammalia: Carnivora) Mammalia 62: 285-95.
4. Mayer WV (1952) The hair of Californian mammals with keys to dorsal guard hairs of Californian mammals Am Midland Nat 48: 480-512.

5. Meyer W, Seger H, Hülmann G, Neurand K (1997) A computer-assisted method for the determination of hair cuticula patterns in mammals. Berl Munch Tierarztl Wochenschr 110: 81-85.

6. Wortmann FJ, Wortmann G, Arns W (1989) Quantitative fiber mixture analysis by scanning electron microscopy. Part II: Blends of wool with Angora rabbit hair Textile Res J 59: 73-80.

7. Wolfe A, Long AM (1997) Distinguishing between the hair fibres of the rabbit and the mountain hare in scats of the red fox. J Zool 242: 370-375.

8. Van den Broeck W, Mortier P, Simoens P (2001) Scanning electron microscopic study of different hair types in various breeds of rabbits. Folia Morphol (Warsz) 60: $33-40$

9. Anica D, Monte LT (2009) Atlas and Key to the hair of terrestrial texas mammals. Special publications museum of Texas Tech University 55: 26.

10. Hausman LA (1920) Structural characteristics of the hair of mammals. American Naturalist 54: 496-523.

11. Hausman LA (1930) Recent studies of hair structure relationships. Science Monthly 30: 258-277.

12. Cole HI (1924) Taxonomic value of hair in Chiroptera. Philippine Journal of Science 14: 117-121.

13. Williams CS (1938) Aids to the identification of mole and shrew hairs with general comments on hair structure and hair determination. Journal of Wildlife Management 2: 239-250.

14. Brown FM (1942) The microscopy of mammalian hair for antropologists Proceedings of the American PhilosophicalSociety 85: 250-274.

15. Corbet LK (1974) Microscopic identification of Hair structure, Australian Mammalian Society: 303

16. Teerink BJ (1991) Hair of West European Mammals: Atlas and Identification Key. Cambridge University Press 1: 156-200.

17. Mathiak HA (1938) A key to hairs of the mammals of southern Michigan Journal of Wildlife Management 2: 251-268.

18. Nason, ES (1948) Morphology of hair eastern North American bats. American Midland Naturalist 39: 345-361.

19. van Staaden M, Jones JK Jr (1997) Comparative morphology of dorsal hai of New World bats of the family Molossidae. in Homenaje al profesor Ticul Alvarez (J Arroyo-Cabrales and OJ Polaco, eds.). Colección Científica, Instituto Nacional de Antropología e Historia, Mexico City, Mexico1: 373-391.

20. Short HL (1978) Analysis of cuticular scales on hairs using the scanning electron microscope. Journal of Mammalogy: 261-268.

21. Amman BR, Owen RD, Bradley RD (2002) Utility of hair structure for taxonomic discrimination in bats, with an example from the bats of Colorado. Occasional Papers of the Museum, Texas Tech University 216: 1-14. 